\title{
Student's Perception towards Sport Skill Program: The Case of Dawuro Zone Some Selected High Schools
}

\author{
Demelash Belayneh Beshir \\ lecturer at Wolaiata Sodo University, Ethiopia
}

\begin{abstract}
The rationale of this study was to check up the student's approach towards sport skill program in Dawuro zone of selected high schools. Besides, the study also intended to assess students' perception towards fitness skill program; to identify association between students' attitude towards physical education and fitness skill programs; to assess students perception towards the importance of the course at local and national levels; to recommend the possible alternative mechanisms and policy interventions that the schools should put in place so as to improve students' attitude towards the subject matter. The study employed descriptive research design and mixed research methods including both qualitative and quantitative method, in which the concerned bodies (teachers and students) were participated. Moreover, the study was conducted in ten (10) secondary schools in Dawuro Zone and participants (physical education teachers and school students). Afterwards, simple random sampling technique of lottery method was used to select students, whereas, comprehensive or availability sampling technique was used to include teachers. Specifically, 30 teachers and 340 students were involved in this study. The relevant data to the study were collected through questionnaire and observation. The collected data were analyzed by using descriptive statistics (percentage, Standard Deviation and Mean Score) and inferential statistics of independent t-test. The findings identified were: negative students 'attitude toward sport skill, student were failed to like teachers teaching method in practical classes, students are reluctant to perform physical activity, students did not takes his/her turn to perform physical activities, factors influence the attitude of high school students towards sport skill were lack of school facilities, cultural influences in school, size of class in school, the poor economic status of students, poor teacher's efficiency, lack of teacher's lesson preparation (readiness), lack of use of teaching methods, lack of gender sensitivity ,lack of interest in subject, peer influence ,absence of dressing house for female student's and students have negative perceptions to the importance of the physical education. The suggested solutions were focused on Physical education teachers should allow students to practice in class and interest as well as their students' interest, the methods and teaching styles used by the teachers should be appropriate with the Physical Education lessons in order to equip students with the necessary knowledge that enable them evaluate the importance of physical education with respect to physical, mental, emotional and social health.
\end{abstract}

Keywords: perception, Physical education, Sport skill

DOI: $10.7176 / \mathrm{JTHS} / 60-01$

Publication date: January $31^{\text {st }} 2022$

\section{INTRODUCTION}

Researchers in the field of Physical Education (PE) indicated that identifying and understanding the factors that are associated with children's physical activity participation are critical to the promotion of current and lifelong physical activity participation (Chung and Phillips, 2002

It is important to understand high school students and perception toward physical education since they will be future members of the work forces, who will need to use their knowledge to maintain a healthy life style. Due to this Content standards are intended to assure that all students meet minimum curriculum requirements, however if students don't find physical education valuable the content standard may have no meaning. Most people have heard the age-old saying Attitude is the key to success various quotes be retrieved that subscribed to this philosophy. In Education researcher suggested that student's attitude towards a subject lead academic success (popham 2005 et.al)

Physical activity can help youth improve their concentration memory and class room behavior. Students who spend more time in physical education class don't have lower test scores than youth who spend less time in physical education class. Physical education program is it is an avenue for engaging in developmentally appropriate physical activities design for children to develop their fitness gross motor skills and health (NASPE, 2012) attitudes flow from beliefs and yield intentions and action .intentions are function of two basic bravery personal attitude toward a behavior and other including peers and parents toward that behavior the first determine is the individual positive or negative evaluation for performing behavior.

NASPE (July 2001), stated that physical education plays a critical role in educating the whole student. Research supports the importance of movement in educating both mind and body .Physical education contributes directly to development of physical competence and fitness. It also helps students to make informed to choice and understand the value of leading a physically active style. The benefits of physical education can affect both academic learning and physical active patterns of students. The healthy physically active students are more likely 
to be academically motivated, alert and successful. In the preschool and primary years, active plays may be positively related to motor abilities and cognitive development. As children grow older and enter adolescence, physically activity may enhance the development of positive self-concepts as well as the ability to pursuer intellectual, social and emotionally challenges throughout the school the school years, quality physical education can promote social, cooperative and problem solving competences. Quality physical education program in our nation schools are essential in developing motor skills, physical fitness and understanding of concept that faster lifelong healthy life style.

Lee (2004) found that the younger children possess more positive attitudes toward physical activity and show more interests toward all kinds of physical activities. However, the reliability of younger children responding to questions might need to be carefully considered due to their lower self-evaluation ability (Lee, 2004). With regard to contextual factors, the quality of physical education programs has been reported to be a strong factor influencing children's ATPEA, Subramaniam and Silverman (2002) indicated that school children's positive attitudes are likely to be associated with enjoyment, perceived usefulness of the curriculum and a sense of belongingness. Curriculum with situational interests, such as those requiring students to analyze and design offensive and defensive strategies, may foster students' interests in physical activity (Chen and Darst, 2001). A learning environment that promotes personal meaning is considered to be important to the development of positive attitudes (Rink, 2006). Children are also likely to become more positive toward physical activity if they are in a learning environment that makes them comfortable and confident (Hagger et al., 2003).

\subsection{Statement of the problem}

Attitude is predisposition or tendency to respond positively or negatively towards a certain area or situation. Attitude influence can individual's choice of action and responses to the challenges incentives and rewards together called stimuli. Attitudes have a powerful influence on behavior. According to Kendra cherry(2008) a psychology experts stated; attitude also can include people issue object, or events .such evaluation are often positive or negative but they can also be uncertain at a time researcher suggest that there are several difficult components that make up attitude.

As Kendra states attitude are also explicit and implicit. Explicit attitude are those that we consciously aware of and that clearly influence over behavior and beliefs. Implicit attitude are unconscious, but still have an effect on one beliefs and behavior. And there are number factor that can influence how and why attitude forms. Those are Experience, Social, Learning. According to (Bob Uri chuck 2015,) the roots spread inward and are anchored in past experience and the fruit branches out ward exposed for all to see. Attitude is both our best friend and our worst enemy. It is more honest and consistent than our word and it is the base for all .We cannot build anything without a solid foundation. There for attitudes have a powerful influence on behaviors .our attitude is 100percent with our control there are plenty of things in life that we have no control over. Majority of students in the study high schools do not give due attention to the subject, not attending it carefully, and hence they have poor result in physical education subject. This problem had also observed among other high school students in Dawuro zone. Therefore my major concern was to assess attitude of students towards sport skill program. It also attempted to identify the possible factors that affect student's attitude toward physical education and sport skill program and to recommend strategies that help them improve their attitude towards subject matter. Based on the stated objectives the study answered the following question, What is the Dawuro Zone high school students 'perception toward physical education subject? What factors influence the perception of high school students towards physical education subject? How do students perceive the importance of the course physical education at local levels? and What possible alternative measures should take so as to enhance students 'perception toward the course P.E?

\subsection{Objectives of the study}

The general objective of this study was to assess the current perception of students toward sport skill program in case of selected high schools of Dawuro zone.

\section{High school student's attitude towards physical education}

There are several variables that influence high school students' attitude towards physical education. As (Barney ,2003) and (Bowyer,1996) in their studied ,high school students have negative attitude towards physical education found that some students did not feel physical education filled need in their lives and consequently did not find it valuable and he concluded that students who were less skilled felt isolated from their peers because there were not readily included for their lack of skill

Finally, Chung and Phillips (2002) found a significant positive relationship between high school student attitudes toward physical education and participation in leisure-time activities. Student beliefs and attitudes impact their behaviors. Insights into these attitudes have implications for curriculum and instructional modification.

More than a third of young people in grades 9-12 do not regularly engage in vigorous-intensity physical activity. Daily participation in high school physical education classes dropped from $42 \%$ in 1991 to $32 \%$ in 2001 
(Centers for Disease Control and Prevention, 2002). National reports document youths' inactive and unhealthy lifestyles and reaffirm the need for increased physical activity among adolescents (U.S. Department of Health and Human Services, 2000). Increased levels of sedentary behaviors among youth indicate a critical need for physical education programs to adopt curriculum that is inclusive of all students and that increases their interest and motivation levels for physical activity participation.

\subsection{Students attitudes towards physical education}

As Hildebrand and Johnson (2002) asserted that at the college level students are more likely to participate if they have positive experience in high schools. That found appositive relationship between the number of years in which students were enrolled in high school physical education and positive attitude towards collage physical education. The study also reported positive relationship between sizes of high school attitude towards collage physical educations.

\subsection{Factors that affecting the implementation of physical education practical session}

\subsubsection{School factors}

Effective schools are distinguished from inefficient once by the frequency and extent to which teachers to learn together ,plan together ,test idea together, discuss practice together ,reflect together, grapple together with the fundamental visions and focus students of developing fullest capacity. Effective schools are learning community place where teachers and administrator study work and learning together with the mission of improving students achievements. All effective schools have culture and it is the information one gets from culture that sends a message. To the students that they will be productive and successful. The effective teacher should be think, reflects, and implements. (Ontario 2010).

\subsubsection{Physical environment}

The physical environment can affect both condition to learning and opportunities for physical activity and health learning .the physical environment includes the school building and ground routes to and from the school. And material and equipment used in school programs. Healthy physical environment would include clean and accessible facilities, shade structures and naturalized play environment. The design of the built environment can enhance restrict opportunities for physical activity and health living (Ontairo 2010).

\subsubsection{The school environment}

The school environment has apposite impact on students learning students are more able and more motivated to do well and achieve their full potential in schools that have appositive school climate and in which they feel safe and supported .school climate may be defined as the sum total of all personal relationships with in school. When these relationships are founded in mutual acceptance and inclusion are modeled by all culture of respect become a norm. Students, teachers, parents can benefits from a social environment and these are various practice that come faster such environment from formal measure e.g. school polices, programs and guide lines that promote inclusion and the removal of systematic barrier to informal behavior such as occurring within unstructured peer interaction or free play(Ontairo2010).

\subsection{The human factors}

\subsubsection{Teachers}

Teaching is a key to students success .teacher are responsible for using appropriate and effective instructional strategies to help students achieve the physical education curriculum expectations as well as appropriate method for assessing and evaluating students learning, teachers bring enthusing addressing individual students need and ensuring high quality learning opportunities for every student's . The attitude with which teacher approach physical education is critical as teacher are important role model for students (Ontairo 2010).

\subsubsection{Students}

Students responsibilities with respect to their own learning gradually and increase overtimes as they progress through elementary and secondary school with appropriate instruction and experience .students come to see how an applied effort can enhance learning and improve achievement as they mature and develop their ability to persists to manage their behavior and impulse to take responsibility risks and to listen with understanding students become better able to take responsibilities for their improvement and achievement in an important part of every students education(Grout and Long 2009)

\section{RESEARCH DESIGN AND METHODOLOGY}

\subsection{The study design}

This research was employed descriptive research design that the researcher believed that it would help to describe the prevailing conditions by triangulating the data collected through qualitative and quantitative method concerning the school students 'attitude toward sport skill with particular reference to secondary schools of Dawuro Zone. 


\subsection{Research method}

This study employed mixed method of research, including qualitative and quantitative method. The quantitative focuses on collecting numerical data by administering questionnaire. By contrast, the qualitative approach tends to be associated with employing observation resulting in open-ended data or textual data. Thirdly, the mixed methods involves collecting data in a simultaneous or sequential manner using methods that are drawn from both quantitative and qualitative traditions in a fashion that best addresses the research question/s (Creswell, 2003). In particular, in order to obtain pertinent data for this study, mixed method was employed that aimed at obtaining both qualitative and quantitative information from the respondents.

\subsection{Sample size and sampling technique}

Out of the 40 secondary schools, 10 secondary schools were included in the study. This is done to get the study groups with common characteristics and to make the study manageable in size. In Ethiopian context, these schools can represent characteristics of both first cycle (grade 9-10) and second cycle (grade 11-12) of the secondary schools. Accordingly, all of the ten secondary schools were selected from Dawuro Zone by using the simple random sampling technique of lottery method. Following selection of the sample schools, participants of the study was selected by using two sampling techniques, namely: availability sampling and simple random sampling. The availability sampling techniques was employed in order to choose the teacher. Gay and Airasian (2003) defined available sampling as one which involves selecting a sample based on small numbers. According to Catherine (2013) described that the correct sample size in a study is dependent on the nature of the population and the purpose of the study. Although there are no general rules, the sample size usually depends on the population to be sampled. In order select representative sample size in the study, the following formula was used for the calculation of the sample size for this study.

$$
\mathrm{n}=\frac{N}{1+N(e) 2} \mathrm{n}=\frac{3800}{1+3800(0.05) 2} \mathrm{n}=\frac{3800}{1+10}=\frac{3800}{11}=\mathbf{3 4 5}
$$

$\mathrm{N}=$ Target Population, which is known (3800); $\mathrm{e}=$ Acceptable sampling error at $5 \%(\mathbf{0 . 0 5})$

From the total population, 345 students were taken simple randomly, 30 physical education teachers were included in the study.

\subsection{Source of data collection}

Questionnaires were used as it is essential to collect data from large number of respondents. It consisted of closedended items. Closed-ended items were offered for respondents as set of alternative to choose one of them to reflect their views. The open-ended items were required the respondents to write their opinions. Questionnaire makes possible an economy of time and expense and also provides a high proportion of usable response (Best \& Kahn, 2003). Moreover, Cohen, Manion\& Morrison (2007) proclaimed that the Likert scale is very quick to grade, and allows the researcher to look at a wide sample of respondents; remove subjective factors from the assessment; measure objectively and get rid of bias and permits more reliable comparison of outcomes across all descriptive statements. The prepared questionnaires for teachers and student were administered at the appropriate time arranged through the joint agreement of the researcher and the respondents. The close-ended questions, such as Likert or rating scales used because they are suitable for large scale survey as they are quick for respondents to answer; they are easy to analyze using statistical techniques. Open ended items are suited to allow a free response. In general, structured questionnaires were used to gather the required information in the study area. The respondents were asked to indicate their degree of agreement using a five point Likert scale ranging from 1 to 5 (where $\mathbf{1}$ =strongly disagree, $\mathbf{2}=$ disagree, $\mathbf{3}=$ undecided, $\mathbf{4}=$ agree, $\mathbf{5}=$ strongly agree).

Finally, the questionnaire was administered to respondents at the appropriate time. The contents of each questionnaire were composed of statements that are aimed to assess the students' attitude to sport skill in selected high school of Dawuro Zone.

\subsection{Pilot Study}

Reliability is the ability of the instrument to give consistent results after a number of repeated trials (Kerlinger, 2003). It was enhanced through use of instrument triangulation technique which is an acceptable technique in survey research that is qualitative in nature since it lends credibility to the findings of the study (Kothari, 2008). In this regard, before to the administration of the questionnaire to the respondents for actual data collection, the pilot test conducted in yamala and Tercha Secondary school in Mareka Woreda and Tercha city administration. This school was selected since it has some common characteristics with the sample schools of the study area.

Accordingly, the draft questionnaire was distributed to 46 student and 5 teacher respondents within the selected school. After the questionnaires were filled and returned back, the validity and reliability of the issues was measured by using Cronbach Alpha. Then, the pilot test results were submitted to the advisor for comment. A reliability coefficient of 0.71 is considered high enough for the instruments to be used for the study (Jwan, 2010). Hence, the analysis was made by using the data gathered from 5 teachers and 46 students. The obtained pilot test 
results of 0.831 and 0.873 respectively of students and teachers. Thus, necessary improvement on issues was made and some items were modified.

Table 1: The Reliability Test Result of Students and Teachers

\begin{tabular}{lllll}
\hline $\mathbf{N}$ & Pilot Groups & Number & Items & Cronbach Alpha \\
\hline $\mathbf{1}$ & Students & 46 & 78 & 0.831 \\
$\mathbf{2}$ & Teachers & 5 & 78 & 0.873 \\
\hline
\end{tabular}

\subsection{Method of data Analysis}

Data from different sources were recorded in readable formats. After preparing and recording raw data in the formats, descriptive and inferential analysis methods were employed. The SPSS Software version 23 was used to analyze raw data. In descriptive analysis, the result was presented through frequency, percentage and mean score. Also independent t-test was used to analysis. The analysis was made with the intention to get the general pictures regarding the effects of student's attitude to sport skill and physical education in the study area. The data that was collected through document analysis and interview was analyzed through narration and description.

\section{Result analysis}

\subsection{Family Background of students}

The following Table illustrates some issues regarding family background of students in Dawuro Zone, which includes family structure and their educational level.

In regarding fathers' education, $30.6 \%(\mathrm{n}=104)$ and $30 \%(\mathrm{n}=102)$ of students reported that their fathers had secondary level of education and certificate holders respectively, while the others, $25.3 \%(n=84)$ and $4.1 \%(n=14)$ responded that their fathers had diploma and degree and above educational level. On the other hand, $10 \%(\mathrm{n}=34)$ of fathers stopped their education at primary level as well as unable to read and write. This shows that majority of fathers were educated in the study area.

As shown in data, $50.3 \%(\mathrm{n}=171)$ of the respondents reported that their mothers were illiterates, while the others, $25.3 \%(n=84)$ were completed primary level of education (grade 1-8). Still, the rests that account, $12.9 \%$ $(n=44)$ of the respondents said that their mothers stopped their education at secondary level. The remaining groups of respondents were reported that their mothers were certificate and diploma holders. Thus, it is possible to conclude that majority of mothers were illiterates as compared to fathers' education which might have adverse effect on learning attitude of students.

As can be seen from the data, 79.1\% $(n=155)$ of teacher respondents responded that the parents' education has a great contribution for the girls education, whereas the others, $20.9 \%(n=41)$ of them oppositely expressed that parental education hardly contribute for girls' education.

One can infer from the above excerpt that parental education has great contribution not only guide their child to be punctilious in the school and to be successful in their education but also it also made them to be a role-model for other illiterate parents to educate their children.

\subsection{Observation data}

Schools, majority of the schools did not have play ground with exception to Tocha, woreda secondary schools. Also, only Loma-woreda secondary school have Availability of teaching materials, mareka Tocha Kechi, and Zuriya secondary school lacks teaching materials and all woreda failed to have enough sport facility. Only Mareka woreda school students wearing appropriate sport clothes during physical education practical classes and the other schools were failed to wear appropriate sport clothes during physical education practical classes in the study area. All sampled secondary school failed to have availability of shower for students, availability of dressing room for students and lack of cooperation between females and males in physical activity program. This implies that the majority of secondary schools in Dawuro Zone were unsuccessful to implement sport skill and PE program effectively and they did not have full of sport materials and playing grounds which in turn have great impact on students' attitude towards to sport skill and physical education.

\subsection{The student attitude in relation to the subject}

The following items are related to the student over all attitudes in relation to the subject in secondary schools. Thus, you are kindly requested to indicate your response by using a " $\sqrt{ }$ " mark on the box placed each item. 
Table 4.4: student over all attitude in relation to the subject in secondary schools

If your response for the item (5=Strongly Agree; 4=Agree, 3=Moderately Agree; 2=Disagree \& 1=Strongly Disagree).

\begin{tabular}{llllllll}
\hline Item & $\mathbf{1}$ & $\mathbf{2}$ & $\mathbf{3}$ & $\mathbf{4}$ & $\mathbf{5}$ & $\mathbf{6}$ & $\mathbf{7}$ \\
\hline t-test & -4.82 & 0.14 & 1.80 & -0.16 & 2.41 & -0.02 & 0.36 \\
P value & 0.00 & 0.89 & 0.07 & 0.87 & 0.01 & 0.98 & 0.71 \\
\hline
\end{tabular}

Key: ${ }^{*}$ statistically significant; $N S=$ Not Significant Teachers $(N=30) ;$ student $(N=340) ; S D=$ Standard Deviation; $M$-Mean Score \& statistically significant at alpha level $(\alpha=0.05)$.

As indicated in the Table 4.4, the calculated value of student $(\mathrm{M}=4.45, \mathrm{SD}=0.49)$, that of teachers $(\mathrm{M}=4.90$, $\mathrm{SD}=0.30)$ and $\mathrm{t}$-test result $(\mathrm{t}=-4.82 ; 0.00<0.05)$ expresses the respondents' agreement to the statement and there is statistically significant mean difference between the responses of teachers and student. This asserts that school students considering physical education as one of the worst lessons in school.

Likewise, the respondents were asked to rate whether student find the activities in physical education as boring because they always do. Accordingly, the calculated mean values of $(\mathrm{M}=4.18, \mathrm{SD}=0.58)$ of student and $(\mathrm{M}=4.16, \mathrm{SD}=0.59)$ of teachers and $\mathrm{t}$-test result $(\mathrm{t}=0.14 ; 0.89>0.05)$ ensures that both groups of respondents' agreement to the statement and the t-test result reveals that there is no statistically significant opinion difference between respondents.

In the same Table of item 3, the respondents were asked to rate their outlook whether students choose \& do what they wish in physical education and games. In this regard, the calculated mean value of $(\mathrm{M}=4.44, \mathrm{SD}=0.73)$ of student and $(\mathrm{M}=4.16, \mathrm{SD}=1.39)$ of teachers and $\mathrm{t}$-test result $(\mathrm{t}=1.80 ; 0.07>0.05)$ affirms that both groups of respondents agreed to the statement and the t-test result reveals that there is no statistically significant variation between the opinions of respondents.

In the same Table of item 4, the respondents were asked to rate their outlook whether student do not go to school to do physical education but to learn other subject in Dawuro Zone. In this regard, the calculated mean value of $(\mathrm{M}=4.48, \mathrm{SD}=0.56)$ of student and $(\mathrm{M}=4.50, \mathrm{SD}=0.57)$ of teacher and t-test result $(\mathrm{t}=-0.16 ; 0.87>0.05)$ affirms that both groups of respondents agreed to the statement and the t-test result reveals that there is no statistically significant variation between the opinions of respondents.

In the same Table of item 5, the respondents ascertained that student have low interest in learning physical education In this regard, the calculated mean value of $(\mathrm{M}=2.84, \mathrm{SD}=1.60)$ of student and $(\mathrm{M}=2.13, \mathrm{SD}=0.86)$ of teachers and $t$-test result $(t=2.41 ; 0.01<0.05)$ affirms that teachers expressed their moderate agreement, while teachers indicated their complete agreement to the statement. Moreover, the t-test result reveals that there is statistically significant variation between the opinions of respondents.

Likewise, the respondents were asked to rate whether student have high level of confidence in participating in physical exercise. Accordingly, the calculated mean values of $(\mathrm{M}=2.59, \mathrm{SD}=1.39)$ of student and $(\mathrm{M}=2.60$, $\mathrm{SD}=1.37)$ of teachers and t-test result $(\mathrm{t}=-0.02 ; 0.98>0.05)$ ensures that both groups of respondents' disagreement to the statement and the t-test result reveals that there is no statistically significant opinion difference between respondents.

In item 7 , the respondents ascertained that student like teachers teaching method in practical classes. The calculated mean value of $(\mathrm{M}=1.81, \mathrm{SD}=0.65)$ of student and $(\mathrm{M}=1.76, \mathrm{SD}=0.62)$ of teachers and $\mathrm{t}$-test result $(\mathrm{t}=$ $0.36 ; 0.71<0.05)$ affirms that teachers expressed their moderate agreement. Moreover, the t-test result reveals that there is statistically significant variation between the opinions of respondents. This indicates that student were failed to like teachers teaching method in practical classes in the study area.

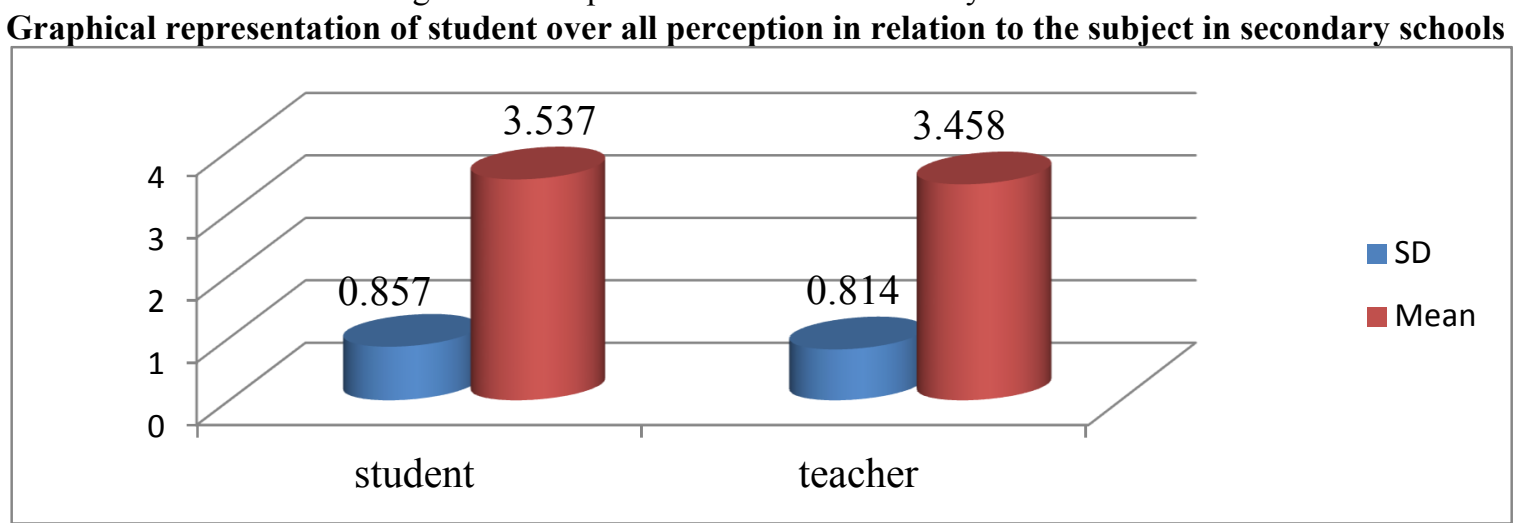

The above graph indicated that the grand mean score of $(\bar{x}=3.54, \mathrm{SD}=0.85)$ of student and $(\bar{x}=3.45, \mathrm{SD}=0.81)$ of teachers was implies the negative attitude in relation to the subject in secondary schools 
Part 2:- Attitude of student's towards physical education teachers

Table 4.5 Attitude of student's towards physical education teachers

\begin{tabular}{llllllllll}
\hline Item & $\mathbf{1}$ & $\mathbf{2}$ & $\mathbf{3}$ & $\mathbf{4}$ & $\mathbf{5}$ & $\mathbf{6}$ & $\mathbf{7}$ & $\mathbf{8}$ & $\mathbf{9}$ \\
\hline t-test & -0.58 & 0.63 & 1.54 & 3.06 & 1.56 & -1.43 & -0.27 & 1.20 & -0.12 \\
p-value & 0.55 & 0.52 & 0.12 & 0.00 & 0.12 & 0.15 & 0.78 & 0.23 & 0.96 \\
\hline
\end{tabular}

Key: *statistically significant; NS=Not Significant Teachers $(N=30) ;$ student $(N=340) ; S D=$ Standard Deviation; $M$-Mean Score \& statistically significant at alpha level $(\alpha=0.05)$.

As described in Table 4.5, the respondents were enquired to rate whether the teachers treat people who are good at physical education differently from others. The calculated mean value of $(\mathrm{M}=1.94, \mathrm{SD}=1.42)$ of student and $(\mathrm{M}=2.10, \mathrm{SD}=1.32)$ of teachers and t-test result $(\mathrm{t}=-0.58 ; 0.55>0.05)$ affirms their disagreement. Also, the $\mathrm{t}$ test result further strengthens that there is no statistical significance of the responses of two groups.

In the same table the respondents were asked the statement that aimed to recognize whether physical education teacher offering extra activities for all children. Accordingly, mean values of $(\mathrm{M}=1.80, \mathrm{SD}=1.17)$ of students respondents and $(\mathrm{M}=1.66, \mathrm{SD}=1.12)$ of teachers along with $\mathrm{t}$ - test result $(\mathrm{t}=0.63 ; 0.52>0.05)$ asserted the respondents expressed their disagreement to the statement. The computed t-test result also manifests the absence of statistical significance of the responses of teachers and students.

Moreover, the respondents were also enquired to rate if only the good pupils are picked for a school team by the physical education teacher. The mean results $(\mathrm{M}=2.18, \mathrm{SD}=1.45)$ of students respondents and $(\mathrm{M}=1.76$, $\mathrm{SD}=1.13)$ of teachers and t-test result $(\mathrm{t}=1.54 ; 0.12>0.05)$ further illustrates that both group respondents' agreement to the statement and non-significant mean variation between the responses of the respondents.

In similar fashion, the respondents were enquired to rate weather students like physical education teacher in the secondary school of Dawuro zone. As a result, the mean results $(\mathrm{M}=2.71, \mathrm{SD}=1.30)$ of teachers and $(\mathrm{M}=1.96$, $\mathrm{SD}=0.93)$ and $\mathrm{t}$-test result $(\mathrm{t}=3.06 ; 0.00<0.05)$ expresses the joint disagreement of two groups and statistical significant mean difference between the responses of teachers and student.

In similar vein, the respondents were asked to rate whether the physical education teachers are only concerned with muscle building. Both respondents rated above average and specifically, student respondents $(\mathrm{M}=3.96$, $\mathrm{SD}=0.90)$, teachers $(\mathrm{M}=3.70, \mathrm{SD}=0.46)$, and $\mathrm{t}$-test result $(\mathrm{t}=1.56 ; 0.12>0.05)$ which revealed that there is no significant mean difference between two groups of respondents.

In other way, the respondents were asked to rate whether the parents of student encourage participating and studying physical education. In view of that, both respondents rated below average and specifically, student respondents $(\mathrm{M}=1.27, \mathrm{SD}=0.44)$, teachers $(\mathrm{M}=1.40, \mathrm{SD}=0.49)$ and $\mathrm{t}$-test result $(\mathrm{t}=-1.43 ; 0.15>0.05)$ which revealed that there is no significant mean difference between two groups of respondents.

In similar vein, the respondents were asked to rate whether the culture encourages participation in physical education. In view of that, both respondents rated below average and specifically, student respondents $(\mathrm{M}=1.24$, $\mathrm{SD}=0.43)$, teachers $(\mathrm{M}=1.26, \mathrm{SD}=0.45)$ and $\mathrm{t}$-test result $(\mathrm{t}=-0.27 ; 0.78>0.05)$ which revealed that there is no significant mean difference between two groups of respondents.

In the same table of item 8, the respondents were asked to ensure whether parents think that physical education lessons are necessary for all pupils in the study area. Consequently, The calculated values of student respondents $(\mathrm{M}=1.34, \mathrm{SD}=0.47)$, teachers $(\mathrm{M}=1.23, \mathrm{SD}=0.43)$ and $\mathrm{t}$-test result $(\mathrm{t}=1.20 ; 0.23>0.05)$ shows that there is no statistically significant difference between the responses of teachers and student.

In the same table of item 9, the respondents were asked to ensure whether parents are pleased when student participate in physical education in the study area. Consequently, The calculated values of $(\mathrm{M}=1.86, \mathrm{SD}=0.35)$ of student and $(\mathrm{M}=1.87, \mathrm{SD}=0.34)$ of teacher and $\mathrm{t}$-test result $(\mathrm{t}=-0.12 ; 0.96>0.05)$ shows that there is no statistically significant difference between the responses of teachers and students.

Graphical representation for attitude of student`s towards physical education teachers

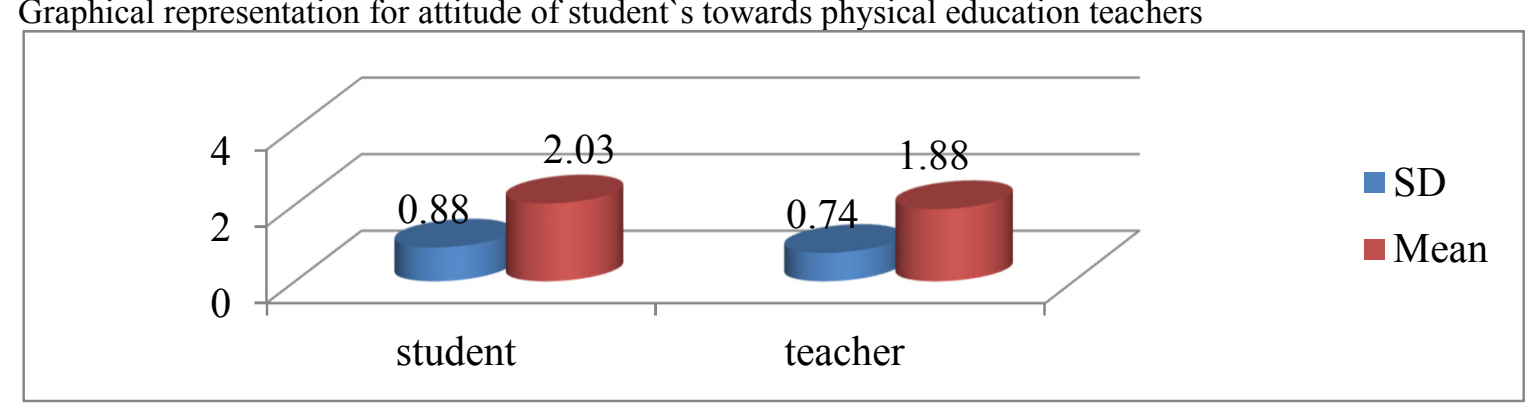

The above graph indicated that the grand mean score of $(\bar{x}=2.03, \mathrm{SD}=0.88)$ of student and $(\bar{x}=1.88, \mathrm{SD}=0.74)$ of teachers was implies the negative attitude of student's towards physical education teachers 
Part: 2.3. Factors that associated to the participation of students in physical education

Table 4.6 participation factors of students in physical education

\begin{tabular}{llllllllllll}
\hline Item & $\mathbf{1}$ & $\mathbf{2}$ & $\mathbf{3}$ & $\mathbf{4}$ & $\mathbf{5}$ & $\mathbf{6}$ & $\mathbf{7}$ & $\mathbf{8}$ & $\mathbf{9}$ & $\mathbf{1 0}$ & $\mathbf{1 1}$ \\
\hline t-test & 0.90 & 1.56 & -0.25 & -3.97 & 6.78 & -11.1 & 0.06 & 0.86 & -2.18 & 0.34 & -4.52 \\
p-value & 0.37 & 0.12 & 0.79 & 0.00 & 0.00 & 0.00 & 0.95 & 0.93 & 0.03 & 0.73 & 0.00 \\
\hline
\end{tabular}

Key: *statistically significant; NS=Not Significant Teachers $(N=30) ;$ student $(N=340) ; S D=$ Standard Deviation; $M$-Mean Score \& statistically significant at alpha level $(\alpha=0.05)$.

As shown in the Table 4.6 above, the respondents were asked to rate whether lack of school facilities has effect on student participation in physical education. Accordingly, the calculated mean value of $(\mathrm{M}=3.98, \mathrm{SD}=0.90)$ of student, whereas $(\mathrm{M}=3.83, \mathrm{SD}=0.65)$ teachers and t-test result $(\mathrm{t}=0.90 ; 0.37>0.05)$ ensures that both groups of respondents agreed to the statement that lack of school facilities has effect on student participation in physical education. The t-test result reveals that there is no statistically significant opinion difference between respondents.

Table 4.6, also indicated that whether cultural influences in school were as major factor that influence student attitude towards to sport skill. The mean result of female students $(M=3.96, S D=0.90)$, teachers $(M=3.70, S D=0.46)$ and $t$-test result $(\mathrm{t}=1.56 ; 0.12>0.05)$ further shows that both group respondents to the statement. In addition, the computed t-test result ascertained that the difference in opinions between both groups of respondents was statistically not significant. Table 4.6, also indicated that whether size of class in school was a major factor that influence student attitude towards to sport skill. The mean result of students $(M=3.95, S D=0.90)$, teachers $(M=4.00$, $\mathrm{SD}=0.91)$ and $\mathrm{t}$-test result $(\mathrm{t}=-0.25 ; 0.79>0.05)$ further shows that both group respondents to the statement. In addition, the computed t-test result ascertained that the difference in opinions between both groups of respondents was statistically not significant. Likewise the other factor that treated in this section was that the poor economic status of students. The mean value of students $(M=3.97, S D=0.90)$, whereas the mean value of teachers $(M=4.63$, $\mathrm{SD}=0.49)$ and $\mathrm{t}$-test result $(\mathrm{t}=-3.97 ; 0.00<0.05)$ manifests that both respondents rated above average. This means both students and teachers accepted the statement. Moreover, the calculated t-test result furthers reveals that there is statistically significant difference between responses of two groups of respondents.

In the same Table of item 5, most of the informants frequently cited the poor teacher's efficiency was a major factor that influence student attitude towards to sport skill in the study area. Moreover, the mean result of student $(\mathrm{M}=4.36, \mathrm{SD}=0.95)$, while mean result of teacher $(\mathrm{M}=3.07, \mathrm{SD}=1.41)$ and $\mathrm{t}$-test result $(\mathrm{t}=6.78 ; 0.00<0.05)$ which explicitly expresses the agreement of two groups of respondents to a given item. Also, the observed t- test result further reveals that there is statistically significant difference between the responses of two groups.

In similar manner, the respondents disagreed with the statement that can be read as lack of teacher's lesson preparation (readiness) was a major factor that influence student attitude towards to sport skill in secondary schools of Dawuro Zone. The calculated mean result student respondents $(\mathrm{M}=4.00, \mathrm{SD}=0.00)$, mean test result of teacher $(\mathrm{M}=4.26, \mathrm{SD}=0.45)$, with $\mathrm{t}$ - test result $(\mathrm{t}=-11.1 ; 0.00>0.05)$ ascertains that the agreement of both groups to the item. Moreover, the computed t- test result strengthened that there is statistically significant difference in opinions between two groups of respondents.

Equally, the respondents were asked to rate whether lack of use of teaching methods was a major factor that influence student attitude towards to sport skill. Consequently, the mean result of the respondents $(\mathrm{M}=4.87$, $\mathrm{SD}=0.33)$ of student and $(\mathrm{M}=4.86, \mathrm{SD}=0.34)$ of teacher along with the $\mathrm{t}$ - test result $(\mathrm{t}=0.06 ; 0.95>0.05)$ which further assures that the respondents agreement to the item and the computed t- test result ascertains that mean differences were not statistically significant. This suggests that lack of use of teaching methods was a major factor that influence student attitude towards to sport skill in the study area.

The participant also ensured lack of gender sensitivity was a major factor that influence student attitude towards to sport skill, the mean result of the respondents $(\mathrm{M}=4.77, \mathrm{SD}=0.42)$ of student and $(\mathrm{M}=4.76, \mathrm{SD}=0.43)$ of teacher along with the $\mathrm{t}$ - test result $(\mathrm{t}=0.86 ; 0.93>0.05)$ which further assures that the respondents agreement to the item and the computed t- test result ascertains that mean differences were not statistically significant.

In the same manner, the respondents also assured lack of interest in subject was a major factor that influence student attitude towards to sport skill in the study area. Explicitly, the mean values for both respondents were above 3.00. The calculated mean values of $(M=3.61, S D=0.67)$ of student and $(M=3.90, S D=0.92)$ of teacher and $\mathrm{t}$-test result $(\mathrm{t}=-2.18 ; 0.03<0.05)$ shows that there is statistically significant difference between the responses of teachers and student.

In the same table of item 10, the respondents were asked to ensure whether the peer influence was a major factor that influence student attitude towards to sport skill in the study area. So, the calculated mean values of $(\mathrm{M}=4.39, \mathrm{SD}=0.94)$ of student and $(\mathrm{M}=4.33, \mathrm{SD}=0.84)$ of teacher and $\mathrm{t}$-test result $(\mathrm{t}=0.34 ; 0.73>0.05)$ ensures that both groups of respondents' agreement to the statement and the t-test result reveals that there is no statistically significant opinion difference between respondents.

Moreover, the obtained data assured that absence of dressing house for female student's was a major factor that influence student attitude towards to sport skill. To see more specifically, the computed t-test result shows there is no statistically significant mean difference among the responses of student and teachers. The data obtained 
from student respondents $(\mathrm{M}=4.31, \mathrm{SD}=0.83)$, whereas that of teacher respondents $(\mathrm{M}=5.00, \mathrm{SD}=0.00)$ and t-test result $(\mathrm{t}=-4.52 ; 0.00<0.05)$ ascertains that the respondents' agreement to the statement and there is significant mean difference between teachers and student.

Graphical representation factors that associated to the participation of students in physical education

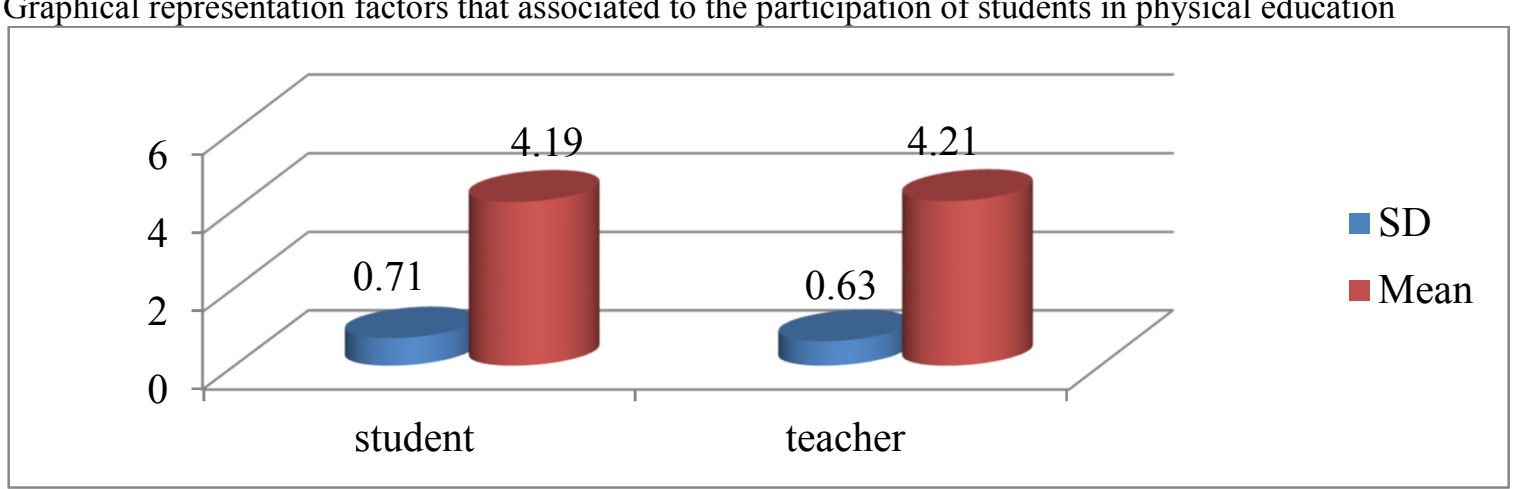

The above graph indicated that the grand mean score of $(\bar{x}=4.19, \mathrm{SD}=0.71)$ of student and $(\bar{x}=4.21, \mathrm{SD}=0.71)$ of teachers was implies the mentioned factor in above table associated to the participation of students in physical education

Part 2.4 Perception in benefits of participating physical education classes

Table 4.7 student perception in benefits of physical education

\begin{tabular}{lllllllllllll}
\hline Item & 1 & 2 & 3 & 4 & 5 & 6 & 7 & 8 & 9 & 10 & 11 & 12 \\
\hline t-test & 3.07 & 6.33 & -0.12 & -9.22 & -2.20 & 4.09 & -13.8 & 3.03 & 6.32 & -16.1 & 7.30 & 3.53 \\
p-value & 0.00 & 0.00 & 0.90 & 0.00 & 0.03 & .030 & .000 & .003 & 0.00 & .000 & 0.00 & 0.00
\end{tabular}

Key: *statistically significant; NS=Not Significant Teachers $(N=30) ;$ student $(N=340) ; S D=$ Standard Deviation; M-Mean Score \& statistically significant at alpha level $(\alpha=0.05)$.

As shown in the Table 4.7 above, the respondents affirmed that physical education provides important contributions to mental health, which was indicated concisely in the above table and the mean result less than 2.50 . The mean result student $(\mathrm{M}=2.32, \mathrm{SD}=1.39)$, the mean result of teachers $(\mathrm{M}=1.53, \mathrm{SD}=0.50)$ and $\mathrm{t}$ - test result $(\mathrm{t}=3.07 ; 0.00<0.05)$ shows that both groups of respondents disagreement to the statement. Additionally, the computed t- test result further illustrates that there is statistically significant difference between the responses of two groups.

In the same Table of item 2, most of the informants frequently cited the negative perception of student to physical education in cooperation enhancement in the study area. Particularly, the mean result of student $(\mathrm{M}=1.84$, $\mathrm{SD}=0.38)$, while mean result of teacher $(\mathrm{M}=1.36, \mathrm{SD}=0.49)$ and $\mathrm{t}$-test result $(\mathrm{t}=6.33 ; 0.00>0.05)$ which explicitly expresses the disagreement of two groups of respondents to a given item. Also, the observed t- test result further reveals that there is no statistically significant difference between the responses of two groups. This assures the negative perception of student to physical education in cooperation enhancement in the study area.

In similar manner, the respondents disagreed with the statement that can be read as there are a large variety of interesting activities offered in secondary schools of Dawuro Zone. The calculated mean result student respondents $(\mathrm{M}=1.86, \mathrm{SD}=0.35)$, mean test result of teacher $(\mathrm{M}=1.87, \mathrm{SD}=0.36)$, with $\mathrm{t}$ - test result $(\mathrm{t}=-0.12$; $0.90>0.05$ ) ascertains that the disagreement of both groups to the item. Moreover, the computed t- test result strengthened that there is no statistically significant difference in opinions between two groups of respondents. Thus, the above data revealed that majority of respondents indicated student perceives that physical education class failed offer large variety of interesting activities in the study area.

Equally, the respondents were asked to rate whether most girls and boys enjoyed physical education classes. Consequently, the mean result of the respondents $(M=1.87, S D=0.33)$ of student and $(M=2.60, S D=0.93)$ of teacher along with the $\mathrm{t}$ - test result $(\mathrm{t}=-9.22 ; 0.00<0.05)$ which further assures that the respondents disagreement to the item and the computed $t$ - test result ascertains that mean differences were statistically significant.

The participant also ensured physical education is one of the best lessons which student has in school. Consequently, the mean result of the respondents $(\mathrm{M}=1.84, \mathrm{SD}=0.39)$ of student and $(\mathrm{M}=2.00, \mathrm{SD}=0.00)$ of teacher along with the $\mathrm{t}$ - test result $(\mathrm{t}=-2.20 ; 0.03<0.05)$ which further assures that the respondents disagreement to the item and the computed $\mathrm{t}$ - test result ascertains that mean differences were statistically significant.

In the same manner, the respondents also assured that activities provided opportunities for satisfying social experiences in the study area. Explicitly, the mean values for both respondents were below 3.00. The calculated mean values of $(\mathrm{M}=2.03, \mathrm{SD}=0.56)$ of student and $(\mathrm{M}=1.60, \mathrm{SD}=0.50)$ of teacher and $\mathrm{t}$-test result $(\mathrm{t}=4.09$; $-.03<0.05$ ) shows that there is statistically significant difference between the responses of teachers and student.

In the same table of item 7 , the respondents were asked to ensure whether physical education offers training 
for leadership in the study area. So, the calculated mean values of $(\mathrm{M}=1.84, \mathrm{SD}=0.56)$ of student and $(\mathrm{M}=3.66$, $\mathrm{SD}=1.56)$ of teacher and t-test result $(\mathrm{t}=-13.8 ; 0.00<0.05)$ ensures that students respondents' disagreement to the statement and the t-test result reveals that there is statistically significant opinion difference between respondents. From this one can infer from the above information that student perceives physical education did not offers training for leadership in the study area.

Moreover, the obtained data assured that physical education is not important because it does not lead to a job. To see more specifically, the computed t-test result shows there is no statistically significant mean difference among the responses of student and teachers. The data obtained from student respondents $(\mathrm{M}=2.40, \mathrm{SD}=1.09)$, whereas that of teacher respondents $(\mathrm{M}=1.80, \mathrm{SD}=0.40)$ and $\mathrm{t}$-test result $(\mathrm{t}=3.03 ; 0.00>0.05)$ ascertains that the respondents' disagreement to the statement and there is significant mean difference between teachers and student.

In the same table of item 9, the respondents were asked to ensure whether physical education activities provided were fun in the study area. So, the calculated mean values of $(\mathrm{M}=1.79, \mathrm{SD}=0.40)$ of student and $(\mathrm{M}=1.30$, $\mathrm{SD}=0.46)$ of teacher and t-test result $(\mathrm{t}=6.32 ; 0.00<0.05)$ ensures that both groups of respondents' disagreement to the statement and the t-test result reveals that there is no statistically significant opinion difference between respondents. From this one can infer from the above information that physical education activities provided were not fun in the study area.

The participant also ensured physical education class provided to compete against their friends. Consequently, the mean result of the respondents $(\mathrm{M}=1.82, \mathrm{SD}=0.38)$ of student and $(\mathrm{M}=3.66, \mathrm{SD}=1.68)$ of teacher along with the $\mathrm{t}$ - test result $(\mathrm{t}=-16.1 ; 0.00<0.05)$ which further assures that the respondents disagreement and agreement of teachers to the item and the computed t- test result ascertains that mean differences were statistically significant. This suggests that physical education class provided to compete against their friends in the study area.

Likewise, the respondents were asked to rate whether there is emotional development promotion in physical education program. Consequently, the mean result of the respondents $(\mathrm{M}=1.98, \mathrm{SD}=0.49)$ of student and $(\mathrm{M}=1.30$, $\mathrm{SD}=0.47)$ of teacher along with the $\mathrm{t}$ - test result $(\mathrm{t}=7.30 ; 0.00<0.05)$ which further assures that the respondents disagreement to the item and the computed t- test result ascertains that mean differences were statistically significant.

Finally, the respondents were asked to rate whether physical education create opportunity in developing moral $\&$ ethical conduct. Consequently, the mean result of the respondents $(\mathrm{M}=1.86, \mathrm{SD}=0.65)$ of student and $(\mathrm{M}=1.43$, $\mathrm{SD}=0.57)$ of teacher along with the $\mathrm{t}$ - test result $(\mathrm{t}=3.53 ; 0.00<0.05)$ which further assures that the respondents disagreement to the item and the computed t- test result ascertains that mean differences were statistically significant.

Graphical representation student perception in benefits of physical education

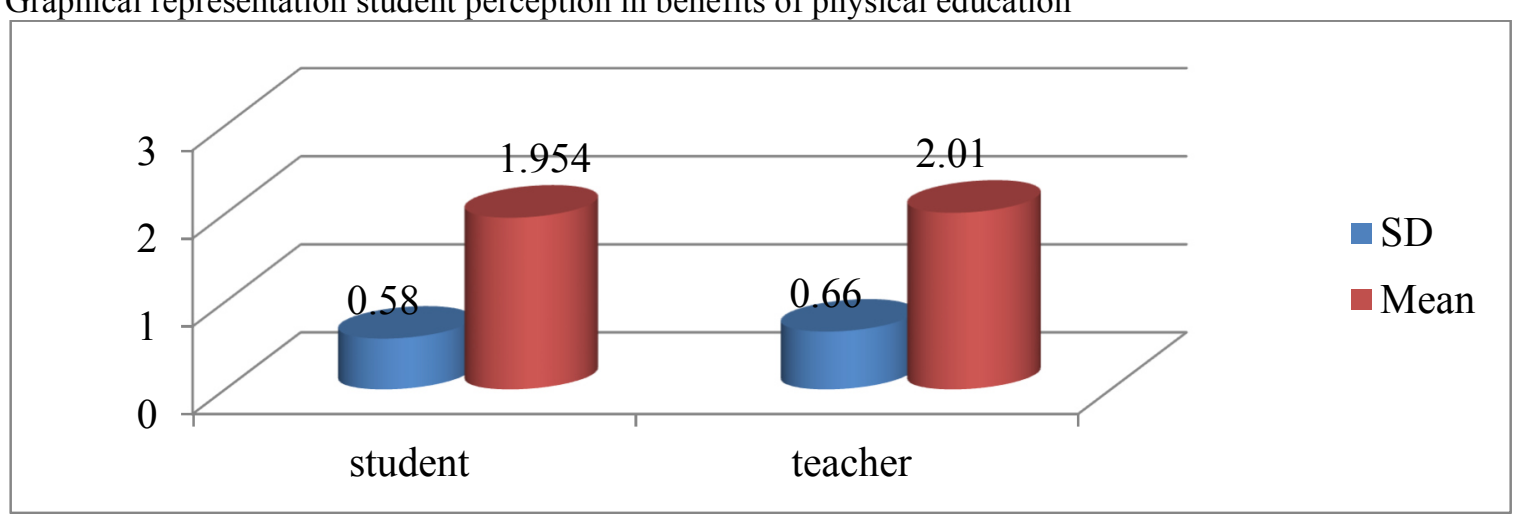

The above graph indicated that the grand mean score of $(\bar{x}=1.95, \mathrm{SD}=0.58)$ of student and $(\bar{x}=2.01, \mathrm{SD}=0.74)$ of teachers was implies the negative student perception in benefits of physical education

Part: 2.5 . The Correlation between attitude towards sport skill and the actual practice Table 4.8; Teachers role to enhance student attitude to sport skill actual practice

\begin{tabular}{lllllllll}
\hline Item & 1 & 2 & 3 & 4 & 5 & 6 & 7 & 8 \\
\hline t-test & 5.69 & 3.47 & -1.03 & 6.53 & 4.17 & 6.93 & 3.60 & 2.06 \\
p-value & .000 & .00 & 0.30 & 0.00 & 0.00 & 0.00 & 0.00 & 0.04 \\
\hline
\end{tabular}

Key: *statistically significant; NS=Not Significant Teachers $(N=30) ;$ student $(N=340) ; S D=$ Standard Deviation; M-Mean Score \& statistically significant at alpha level $(\alpha=0.05)$.

As shown in the Table 4.8 above, the respondents affirmed that teacher allows students to share their ability with partners, which was indicated concisely in the above table and the mean result less than 2.50 . The mean result student $(\mathrm{M}=2.04, \mathrm{SD}=0.55)$, the mean result of teachers $(\mathrm{M}=1.40, \mathrm{SD}=0.93)$ and $\mathrm{t}$ - test result $(\mathrm{t}=5.69 ; 0.00<0.05)$ shows that both groups of respondents disagreement to the statement. Additionally, the computed t- test result 
further illustrates that there is statistically significant difference between the responses of two groups. This affirms that teachers were failed to allow students to share their ability with partners in the study area.

In the same Table of item 2, most of the informants frequently cited teacher encourages students to perform physical activity in the study area. Particularly, the mean result of student $(\mathrm{M}=2.02, \mathrm{SD}=0.45)$, while mean result of teacher $(\mathrm{M}=1.70, \mathrm{SD}=0.79)$ and $\mathrm{t}$-test result $(\mathrm{t}=3.47 ; 0.00<0.05)$ which explicitly expresses the disagreement of two groups of respondents to a given item. Also, the observed t- test result further reveals that there is statistically significant difference between the responses of two groups.

In similar manner, the respondents disagreed with the statement that can be read as teacher show each and every thing for the students in secondary schools of Dawuro Zone. The calculated mean result student respondents $(\mathrm{M}=1.93, \mathrm{SD}=0.64)$, mean test result of teacher $(\mathrm{M}=2.06, \mathrm{SD}=1.17)$, with $\mathrm{t}$ - test result $(\mathrm{t}=-1.03 ; 0.30>0.05)$ ascertains that the disagreement of both groups to the item. Moreover, the computed t- test result strengthened that there is no statistically significant difference in opinions between two groups of respondents.

Equally, the respondents were asked to rate whether teachers facilitates and assists the students while they are doing a given activities. Consequently, the mean result of the respondents $(\mathrm{M}=2.00, \mathrm{SD}=0.55)$ of student and $(\mathrm{M}=1.26, \mathrm{SD}=0.90)$ of teacher along with the $\mathrm{t}$ - test result $(\mathrm{t}=6.53 ; 0.00<0.05)$ which further assures that the respondents disagreement to the item and the computed t- test result ascertains that mean differences were statistically significant.

The participant also ensured the failure of teachers to correct the errors of students at the end of physical activity. Consequently, the mean result of the respondents $(\mathrm{M}=2.06, \mathrm{SD}=0.54)$ of student and $(\mathrm{M}=1.60, \mathrm{SD}=0.93)$ of teacher along with the $t$ - test result $(t=4.17 ; 0.00<0.05)$ which further assures that the respondents disagreement to the item and the computed t- test result ascertains that mean differences were statistically significant.

In the same manner, the respondents also assured failure of teachers initiating passive students to take part in tasks execution in the study area. Explicitly, the mean values for both respondents were below 3.00. The calculated mean values of $(\mathrm{M}=1.98, \mathrm{SD}=0.50)$ of student and $(\mathrm{M}=1.26, \mathrm{SD}=0.90)$ of teacher and $\mathrm{t}$-test result ( $\mathrm{t}=6.93$; $0.00<0.05$ ) shows that there is statistically significant difference between the responses of teachers and student.

In the same table of item 7, the respondents were asked to ensure whether teacher helps his/her students to participate actively in physical activity in the study area. So, the calculated mean values of $(\mathrm{M}=2.02, \mathrm{SD}=0.57)$ of student and $(\mathrm{M}=1.60, \mathrm{SD}=0.93)$ of teacher and t-test result $(\mathrm{t}=3.60 ; 0.00<0.05)$ ensures that both groups of respondents' disagreement to the statement and the t-test result reveals that there is statistically significant opinion difference between respondents. Moreover, the obtained data assured that teachers failed to corrects the skill errors during physical activity. To see more specifically, the computed t-test result shows there is statistically significant mean difference among the responses of student and teachers. The data obtained from student respondents $(\mathrm{M}=1.83, \mathrm{SD}=0.56)$, whereas that of teacher respondents $(\mathrm{M}=1.60, \mathrm{SD}=0.93)$ and $\mathrm{t}$-test result $(\mathrm{t}=2.06 ; 0.04>0.05)$ ascertains that the respondents' disagreement to the statement and there is significant mean difference between teachers and student.

Graphical repersentation Teachers role to enhance student attitude to sport skill actual practice

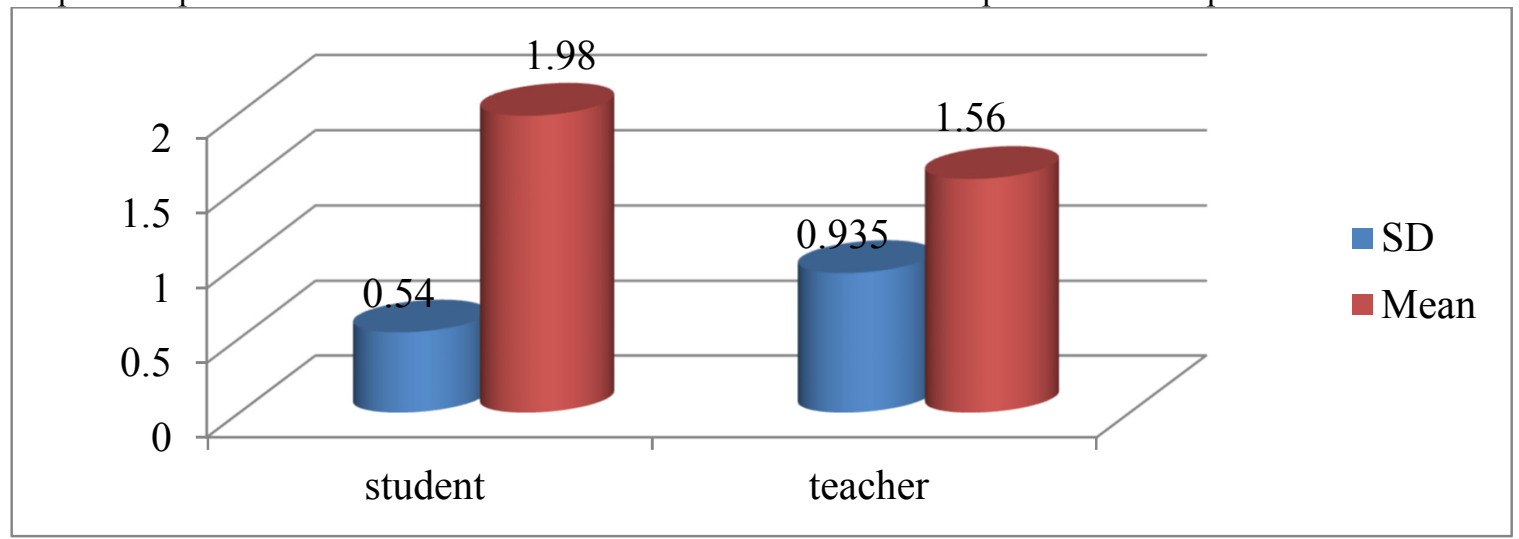

The above graph indicated that the grand mean score of $(\bar{x}=1.98, \mathrm{SD}=0.54)$ of student and $(\bar{x}=1.56, \mathrm{SD}=0.93)$ of teachers was implies teachers not played role to enhance student attitude to sport skill actual practice Table.4.9 Student's Activity towards sport skill and the actual practice

\begin{tabular}{llllllll}
\hline Item & 1 & 2 & 3 & 4 & 5 & 6 & 7 \\
\hline t-test & 0.06 & -3.6 & 2.42 & 2.71 & 3.69 & 1.79 & 0.01 \\
p-value & 0.95 & 0.00 & 0.02 & 0.00 & 0.00 & 0.07 & 0.99 \\
\hline
\end{tabular}

Key: *statistically significant; NS=Not Significant Teachers $(N=30) ;$ student $(N=340) ; S D=$ Standard Deviation; M-Mean Score \& statistically significant at alpha level $(\alpha=0.05)$.

As shown in the Table 4.9 above, the respondents affirmed that students are reluctant to perform physical 
activity, which was indicated concisely in the above table and the mean result above 2.50 . As we can read from the mean result student $(\mathrm{M}=4.31, \mathrm{SD}=0.97)$, the mean result of teachers $(\mathrm{M}=4.30, \mathrm{SD}=1.44)$ and $\mathrm{t}$ - test result $(\mathrm{t}=0.06 ; 0.95>0.05)$ shows that both groups of respondents agreement to the statement. Additionally, the computed $\mathrm{t}$ - test result further illustrates that there is no statistically significant difference between the responses of two groups.

In the same Table of item 2, most of the informants frequently cited each students did not takes his/her turn to perform physical activities in the study area. Particularly, the mean result of student $(\mathrm{M}=3.92, \mathrm{SD}=0.47)$, while mean result of teacher $(\mathrm{M}=4.33, \mathrm{SD}=1.37)$ and $\mathrm{t}$-test result $(\mathrm{t}=-3.60 ; 0.00<0.05)$ which explicitly expresses the agreement of two groups of respondents to a given item. Also, the observed t- test result further reveals that there is statistically significant difference between the responses of two groups.

In similar manner, the respondents agreed with the statement that can be read as students do as they wish rather than about a given task in secondary schools of Dawuro Zone. Above all, the computed t- test result strengthened that there is statistically significant difference in opinions between two groups of respondents.

Equally, the respondents were asked to rate whether student did not ask their teacher to help them during learning task. Consequently, the mean result of the respondents $(\mathrm{M}=4.54, \mathrm{SD}=0.73)$ of student and $(\mathrm{M}=4.13$, $\mathrm{SD}=1.33)$ of teacher along with the $\mathrm{t}$ - testresult $(\mathrm{t}=2.71 ; 0.00<0.05)$ which further assures that the respondents agreement to the item and the computed t- test result ascertains that mean differences were statistically significant.

The participant also ensured students freely communicate with their teachers and partners. Consequently, the mean result of the respondents $(\mathrm{M}=2.04, \mathrm{SD}=0.59)$ of student and $(\mathrm{M}=1.60, \mathrm{SD}=0.93)$ of teacher along with the $\mathrm{t}$ - test result $(\mathrm{t}=3.69 ; 0.00<0.05)$ which further assures that the respondents disagreement to the item and the computed t- test result ascertains that mean differences were statistically significant.

In the same manner, the respondents also assured students were failed to prepare accuracy over physical activity in the study area. Explicitly, the mean values for both respondents were below 3.00. The calculated mean values of $(\mathrm{M}=1.80, \mathrm{SD}=0.57)$ of student and $(\mathrm{M}=1.60, \mathrm{SD}=0.93)$ of teacher and t-test result $(\mathrm{t}=1.79 ; 0.07>0.05)$ shows that there is no statistically significant difference between the responses of teachers and student.

In the same table of item 7, the respondents were asked to ensure whether there is domination of some students during physical activities in the study area. So, the calculated mean values of $(\mathrm{M}=4.14, \mathrm{SD}=0.75)$ of student and $(\mathrm{M}=4.13, \mathrm{SD}=1.33)$ of teacher and t-test result $(\mathrm{t}=0.01 ; 0.99>0.05)$ ensures that both groups of respondents' agreement to the statement and the t-test result reveals that there is no statistically significant opinion difference between respondents. From this one can infer from the above information that there is domination of some students during physical activities in the study area.

Graphical representation of Student's Activity towards sport skill and the actual practice

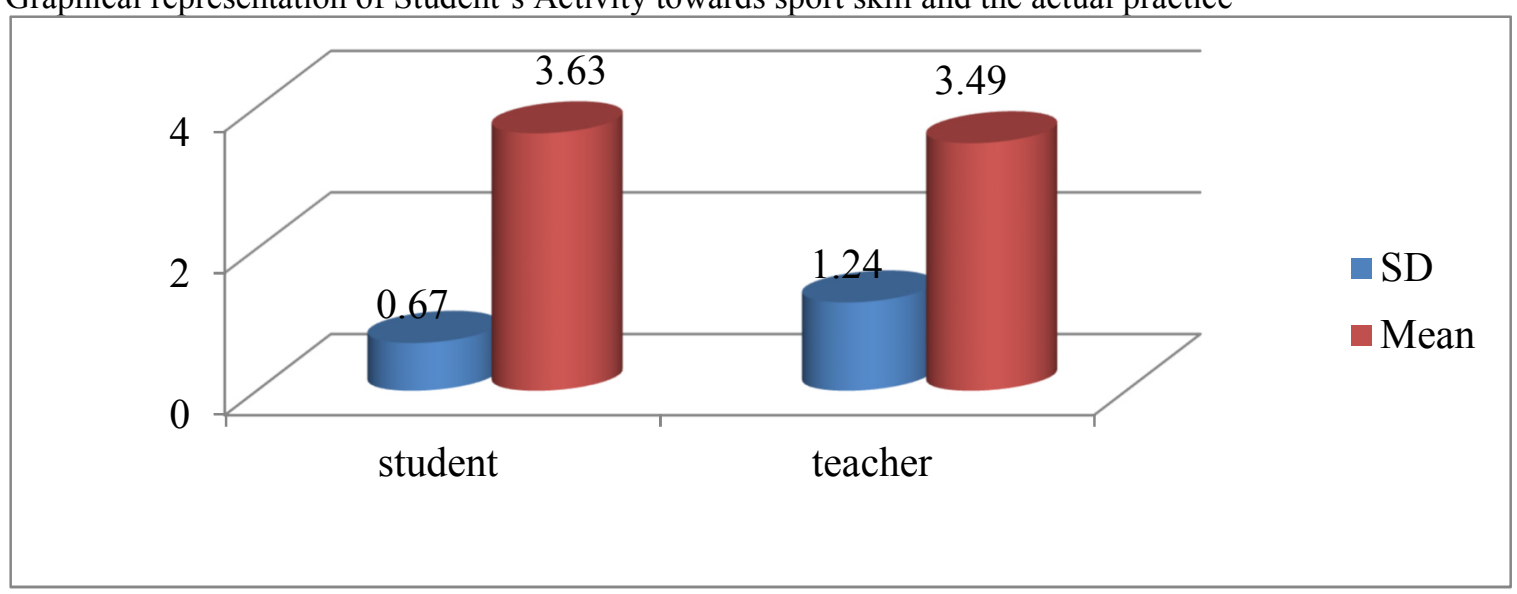

The above graph indicated that the grand mean score of $(\bar{x}=3.63, \mathrm{SD}=0.67)$ of student and $(\bar{x}=4.49, \mathrm{SD}=1.24)$ of teachers was implies the negative attitude of students towards sport skill and the actual practice

\begin{tabular}{llllll}
\hline Item & 1 & 2 & 3 & 4 & 5 \\
\hline t-test & 5.43 & 6.94 & 7.06 & 4.06 & 2.06 \\
p-value & 0.00 & 0.00 & 0.00 & 0.00 & 0.40 \\
\hline
\end{tabular}

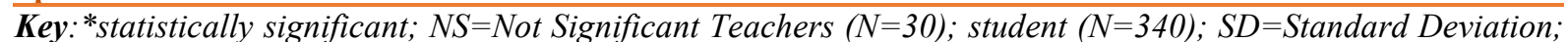
M-Mean Score \& statistically significant at alpha level $(\alpha=0.05)$.

As shown in the Table 4.8 above, the respondents affirmed that the teacher's guide students to perform a physical activity, which was indicated concisely in the above table and the mean result less than 2.50 . The mean result student $(\mathrm{M}=1.83, \mathrm{SD}=0.37)$, the mean result of teachers $(\mathrm{M}=1.43, \mathrm{SD}=0.50)$ and $\mathrm{t}$ - test result $(\mathrm{t}=5.43$; $0.00<0.05)$ shows that both groups of respondents disagreement to the statement. Additionally, the computed $t-$ test result further illustrates that there is no statistically significant difference between the responses of two groups. 
In the same Table of item 2, most of the informants frequently cited students given plenty of time to perform physical activity in the study area. Particularly, the mean result of student $(\mathrm{M}=2.60, \mathrm{SD}=1.23)$, while mean result of teacher $(\mathrm{M}=1.03, \mathrm{SD}=0.18)$ and $\mathrm{t}$-test result $(\mathrm{t}=6.94 ; 0.00<0.05)$ which explicitly expresses the disagreement of two groups of respondents to a given item. Also, the observed t- test result further reveals that there is statistically significant difference between the responses of two groups.

In similar manner, the respondents disagreed with the statement that can be read as students prepare for a task before the task is performed in secondary schools of Dawuro Zone. Above all, the calculated mean result student respondents $(\mathrm{M}=1.93, \mathrm{SD}=0.44)$, mean test result of teacher $(\mathrm{M}=1.26, \mathrm{SD}=0.90)$, with $\mathrm{t}$ - test result $(\mathrm{t}=7.06$; $0.00<0.05)$ ascertains that the disagreement of both groups to the item. Moreover, the computed t- test result strengthened that there is statistically significant difference in opinions between two groups of respondents. Thus, the above data revealed that majority of students were not preparing them for a task before the task is performed in the study area.

Equally, the respondents were asked to rate whether students have the pressure to perform well. Consequently, the mean result of the respondents $(\mathrm{M}=2.00, \mathrm{SD}=0.47)$ of student and $(\mathrm{M}=1.60, \mathrm{SD}=0.93)$ of teacher along with the $\mathrm{t}$ - test result $(\mathrm{t}=4.06 ; 0.00<0.05)$ which further assures that the respondents disagreement to the item and the computed t- test result ascertains that mean differences were statistically significant. This suggests that absence of pressure for students to perform well in the study area.

The participant also ensured that students were patient and sensitive for physical activity. Consequently, the mean result of the respondents $(\mathrm{M}=1.83, \mathrm{SD}=0.56)$ of student and $(\mathrm{M}=1.60, \mathrm{SD}=0.93)$ of teacher along with the $\mathrm{t}$ - test result $(\mathrm{t}=2.06 ; 0.40>0.05)$ which further assures that the respondents disagreement to the item and the computed t- test result ascertains that mean differences were not statistically significant. This suggests that students were not patient and sensitive for physical activity in the study area.

The above grand mean score indicated that $(\bar{x}=2.04, \mathrm{SD}=0.61)$ of student and $(\bar{x}=1.38, \mathrm{SD}=0.68)$ of teachers was implies the negative attitude of student's towards physical education teachers

Table 4.10 Student attitude in relation to challenge of Physical activity

\begin{tabular}{llllllll}
\hline Item & 1 & 2 & 3 & 4 & 5 & 6 & 7 \\
\hline t-test & -2.94 & -7.56 & 4.56 & 0.08 & -3.69 & -0.22 & -0.14 \\
p-value & 0.00 & 0.00 & 0.00 & 0.93 & 0.00 & 0.83 & 0.89 \\
\hline
\end{tabular}

Key: * statistically significant; NS=Not Significant Teachers $(N=30) ;$ student $(N=340) ; S D=$ Standard Deviation; M-Mean Score \& statistically significant at alpha level $(\alpha=0.05)$.

As shown in the Table 4.10 above, the respondents affirmed that students are worried about making mistakes in physical activity program, which was indicated concisely in the above table and the mean result above 2.50 . The mean result student $(M=4.39, S D=0.93)$, the mean result of teachers $(M=4.90, S D=0.30)$ and $t$ - test result $(t=-$ $2.94 ; 0.00<0.05$ ) shows that both groups of respondents agreement to the statement. Additionally, the computed ttest result further illustrates that there is statistically significant difference between the responses of two groups. This affirms students are worried about making mistakes of physical activity program in the study area.

In the same Table of item 2, most of the informants frequently cited students are fearful of injury in the study area. Particularly, the mean result of student $(\mathrm{M}=4.02, \mathrm{SD}=0.17)$, while mean result of teacher $(\mathrm{M}=4.33, \mathrm{SD}=0.47)$ and $t$-test result $(\mathrm{t}=0.76 ; 0.00<0.05)$ which explicitly expresses the agreement of two groups of respondents to a given item. Also, the observed t- test result further reveals that there is statistically significant difference between the responses of two groups. This assures that students are fearful of injury in the study area.

Equally, the respondents were asked to rate whether students lack of prior experience. Consequently, the mean result of the respondents $(\mathrm{M}=4.83, \mathrm{SD}=0.36)$ of student and $(\mathrm{M}=4.50, \mathrm{SD}=0.50)$ of teacher along with the $\mathrm{t}$ - test result $(\mathrm{t}=4.56 ; 0.00<0.05)$ which further assures that the respondents agreement to the item and the computed $\mathrm{t}$ - test result ascertains that mean differences were statistically significant. This suggests that student's lack of prior experience in the study area

In similar manner, the respondents disagreed with the statement that can be read as the little evaluation time due to large group in secondary schools of Dawuro Zone. The calculated mean result student respondents $(\mathrm{M}=$ $4.77, \mathrm{SD}=0.41)$, mean test result of teacher $(\mathrm{M}=4.76, \mathrm{SD}=0.43)$, with $\mathrm{t}$ - test result $(\mathrm{t}=0.08 ; 0.93>0.05)$ ascertains that the agreement of both groups to the item. Moreover, the computed t- test result strengthened that there is no statistically significant difference in opinions between two groups of respondents.

Equally, the respondents were asked to rate whether teacher not played a role in shaping perceptions of pupils towards physical education. Consequently, the mean result of the respondents $(\mathrm{M}=3.66, \mathrm{SD}=0.73)$ of student and $(\mathrm{M}=4.20, \mathrm{SD}=1.06)$ of teacher along with the $\mathrm{t}$ - test result $(\mathrm{t}=-3.69 ; 0.00<0.05)$ which further assures that the respondents agreement to the item and the computed t- test result ascertains that mean differences were statistically significant.

The participant also ensured teacher not demonstrates skills to pupils. Consequently, the mean result of the respondents $(\mathrm{M}=4.39, \mathrm{SD}=0.94)$ of student and $(\mathrm{M}=4.43, \mathrm{SD}=0.93)$ of teacher along with the $\mathrm{t}$ - test result $(\mathrm{t}=-$ 
$0.22 ; 0.83>0.05$ ) which further assures that the respondents disagreement to the item and the computed t- test result ascertains that mean differences were not statistically significant. This suggests that teacher not demonstrate skills to pupils in the study area.

In the same manner, the respondents also assured physical education teachers failed to adapt socially by encouraging them to attempt to inspire each other in many of the activities in the study area. Explicitly, the mean values for both respondents were above 3.00. The calculated mean values of $(\mathrm{M}=4.31, \mathrm{SD}=0.83)$ of student and $(\mathrm{M}=4.33, \mathrm{SD}=0.84)$ of teacher and $\mathrm{t}$-test result $(\mathrm{t}=-0.14 ; 0.89>0.05)$ shows that there is no statistically significant difference between the responses of teachers and student.

In the same table of item 8 , the respondents were asked to ensure whether lack of balance between classroom learning and participation in physical education lessons in the study area. So, the calculated mean values of $(\mathrm{M}=4.32, \mathrm{SD}=1.01)$ of student and $(\mathrm{M}=5.00, \mathrm{SD}=0.00)$ of teacher and t-test result $(\mathrm{t}=-3.61 ; 0.00<0.05)$ ensures that both groups of respondents' agreement to the statement and the t-test result reveals that there is statistically significant opinion difference between respondents.

The above grand mean score indicated that $(\overline{\boldsymbol{x}}=4.33, \mathrm{SD}=0.67)$ of student and $(\overline{\boldsymbol{x}}=4.55, \mathrm{SD}=0.56)$ of teachers was implies student worry to the challenge of Physical activity

Table 4.11 Measure to be taken to improve student attitude towards PE

\begin{tabular}{llllllllllll}
\hline Item & $\mathbf{1}$ & $\mathbf{2}$ & $\mathbf{3}$ & $\mathbf{4}$ & $\mathbf{5}$ & $\mathbf{6}$ & $\mathbf{7}$ & $\mathbf{8}$ & $\mathbf{9}$ & $\mathbf{1 0}$ & $\mathbf{1 1}$ \\
\hline t-test & 0.31 & -0.70 & -0.47 & .000 & -3.12 & -1.29 & -2.67 & -1.21 & -0.60 & -0.23 & 2.36 \\
p-value & 0.76 & 0.48 & 0.64 & .64 & 0.00 & 0.19 & 0.01 & 0.23 & 0.54 & 0.76 & 0.19 \\
\hline
\end{tabular}

Key: *statistically significant; $N S=$ Not Significant Teachers $(N=30) ;$ student $(N=340) ; S D=$ Standard Deviation; $M$-Mean Score \& statistically significant at alpha level $(\alpha=0.05)$.

As shown in the Table 4.11 above, the respondents affirmed that facilitating suitable teaching and learning environment were considered as mechanism to improve students' attitude towards to physical education and sport skill, which was indicated concisely in the above table and the mean result less than 2.50 . The mean result student $(\mathrm{M}=3.64, \mathrm{SD}=1.65)$, the mean result of teachers $(\mathrm{M}=3.73, \mathrm{SD}=1.11)$ and $\mathrm{t}$ - test result $(\mathrm{t}=-0.31 ; 0.76>0.05)$ shows that both groups of respondents agreement to the statement. Additionally, the computed t- test result further illustrates that there is no statistically significant difference between the responses of two groups. This affirms the facilitating suitable teaching and learning environment were considered as mechanism to improve students' attitude towards to physical education and sport skill in the study area.

In the same Table of item 2, most of the informants frequently cited the developing qualified person in the study area. Particularly, the mean result of student $(\mathrm{M}=4.27, \mathrm{SD}=1.43)$, while mean result of teacher $(\mathrm{M}=4.46$, $\mathrm{SD}=0.82)$ and $\mathrm{t}$-test result $(\mathrm{t}=-0.70 ; 0.48>0.05)$ which explicitly expresses the agreement of two groups of respondents to a given item. Also, the observed t- test result further reveals that there is no statistically significant difference between the responses of two groups. This assures the developing qualified person was considered as mechanism to improve students' attitude towards to physical education and sport skill in the study area.

In similar manner, the respondents disagreed with the statement that can be read as making the subject available at regional and national examination in secondary schools of Dawuro Zone. The calculated mean result student respondents $(\mathrm{M}=4.31, \mathrm{SD}=1.36)$, mean testresult of teacher $(\mathrm{M}=4.43, \mathrm{SD}=0.50)$, with $\mathrm{t}$ - test result $(\mathrm{t}=-$ $0.47 ; 0.64>0.05$ ) ascertains that the agreement of both groups to the item. Moreover, the computed t- test result strengthened that there is no statistically significant difference in opinions between two groups of respondents. Thus, the above data revealed that making the subject available at regional and national examination was considered as mechanism to improve students' attitude towards to physical education and sport skill.

Equally, the respondents were asked to rate whether enough time schedules provided for physical education. Consequently, the mean result of the respondents $(\mathrm{M}=4.31, \mathrm{SD}=1.36)$ of student and $(\mathrm{M}=4.33, \mathrm{SD}=1.37)$ of teacher along with the $\mathrm{t}$ - test result $(\mathrm{t}=0.00 ; 0.64>0.05)$ which further assures that the respondents agreement to the item and the computed t- test result ascertains that mean differences were not statistically significant. This suggests that providing enough time schedules for physical education was considered as mechanism to improve students' attitude towards to physical education and sport skill in the study area.

The participant also ensured physical education activity skill should be well executed. Consequently, the mean result of the respondents $(\mathrm{M}=3.62, \mathrm{SD}=1.63)$ of student and $(\mathrm{M}=4.56, \mathrm{SD}=0.50)$ of teacher along with the $\mathrm{t}$ test result $(\mathrm{t}=-3.12 ; 0.00>0.05)$ which further assures that the respondents disagreement to the item and the computed $t$ - test result ascertains that mean differences were not statistically significant. This suggests that physical education activity skill should be well executed was considered as mechanism to improve students' attitude towards to physical education and sport skill in the study area.

In the same manner, the respondents also assured the teacher should vary skills taught so that pupils learn with ease physical education skills taught was considered as mechanism to improve students' attitude towards to physical education and sport skill in the study area. Explicitly, the mean values for both respondents were above 3.00. The calculated mean values of $(M=4.25, S D=1.43)$ of student and $(M=4.60, S D=0.50)$ of teacher and t-test result $(\mathrm{t}=-1.29 ; 0.19>0.05)$ shows that there is no statistically significant difference between the responses of 
teachers and student.

In the same table of item 7 , the respondents were asked to ensure whether teacher should take into account differences in pupils abilities so that all are involved in the physical education lesson in the study area. So, the calculated mean values of $(\mathrm{M}=3.60, \mathrm{SD}=1.67)$ of student and $(\mathrm{M}=4.43, \mathrm{SD}=0.77)$ of teacher and $\mathrm{t}$-test result $(\mathrm{t}=-$ $2.67 ; 0.01<0.05)$ ensures that both groups of respondents' agreement to the statement and the t-test result reveals that there is statistically significant opinion difference between respondents. From this one can infer from the above information that teacher should take into account differences in pupils abilities so that all are involved in the physical education lesson was considered as mechanism to improve students' attitude towards to physical education and sport skill in the study area.

Moreover, the obtained data assured that teacher should regularly correct pupils in their execution of physical education skills to perform them correctly was considered as mechanism to improve students' attitude towards to physical education and sport skill. The computed t-test result shows there is no statistically significant mean difference among the responses of student and teachers. The data obtained from student respondents $(\mathrm{M}=4.15$, $\mathrm{SD}=1.40)$, whereas that of teacher respondents $(\mathrm{M}=4.47, \mathrm{SD}=1.13)$ and $\mathrm{t}$-test result $(\mathrm{t}=-1.21 ; 0.23>0.05)$ ascertains that the respondents' agreement to the statement and there is no significant mean difference between teachers and student.

In the same table of item 9, the respondents were asked to ensure whether teacher should use all the physical education lessons to teach pupils the subject in the study area. So, the calculated mean values of $(\mathrm{M}=4.21, \mathrm{SD}=1.36)$ of student and $(\mathrm{M}=4.36, \mathrm{SD}=0.99)$ of teacher and $\mathrm{t}$-test result $(\mathrm{t}=-0.60 ; 0.54>0.05)$ ensures that both groups of respondents' agreement to the statement and the t-test result reveals that there is no statistically significant opinion difference between respondents. From this one can infer from the above information that teacher should use all the physical education lessons to teach pupils the subject was considered as mechanism to improve students' attitude towards to physical education and sport skill in the study area.

In the same manner, the respondents also assured that teacher should conduct physical education lesson as seriously as was considered as mechanism to improve students' attitude towards to physical education and sport skill. Explicitly, the mean values for both respondents were above 3.00. The calculated mean values of $(\mathrm{M}=4.25$, $\mathrm{SD}=1.30)$ of student and $(\mathrm{M}=4.33, \mathrm{SD}=1.37)$ of teacher and t-test result $(\mathrm{t}=-0.23 ; 0.76>0.05)$ shows that there is no statistically significant difference between the responses of teachers and student.

Finally, the respondents also assured that physical education subject should be included in the program of every school were considered as mechanism to improve students' attitude towards to physical education and sport skill. Explicitly, the mean values for both respondents were above 3.00. The calculated mean values of $(\mathrm{M}=3.77$, $\mathrm{SD}=0.59)$ of student and $(\mathrm{M}=3.50, \mathrm{SD}=0.49)$ of teacher and $\mathrm{t}$-test result $(\mathrm{t}=2.36 ; 0.19>0.05)$ shows that there is no statistically significant difference between the responses of teachers and student.

The above grand mean score indicated that $(\bar{x}=4.04, \mathrm{SD}=1.38)$ of student and $(\bar{x}=4.29, \mathrm{SD}=0.88)$ of teachers was implies the measure to be taken to improve student attitude towards $\mathrm{PE}$

\section{Summary and Recommendations}

The main aim of this study was to assess the current attitude of students toward physical education and sport skill program in case of selected high schools of Dawuro zone. In order to attain the desired objectives: to identify students' attitude towards physical education course and fitness skill program in case of selected high schools of Dawuro zone. To identify association between students' attitude towards physical education and fitness skill programs in selected high schools of Dawuro zone, to recommend the possible alternative mechanisms and policy interventions that the schools should put in place so as to improve students' attitude towards the subject matter. This study was intended to answer the following basic research question in order to attain the desired objectives: (a) what is the Dawuro Zone high school students 'attitude toward physical education subject? (b)What factors influence the attitude of high school students towards physical education subject? (c) How do students perceive the importance of the course physical education at local levels? (d) What possible alternative measures should take so as to enhance students 'attitude toward physical education? In order to get answers to the questions qualitative and quantitative data collected from secondary and primary sources through questionnaire and observation. Then, following procedures were undertaken: the problem area and study site was identified, relevant documents were examined from various prevalent sources; questions were prepared and distributed to the sample populations, sample populations were determined, the study area was delimited, tools for data collection (questionnaire, and observation) were developed and administered to the sample groups and finally the data was analyzed and interpreted.

The study took place in ten (10) secondary schools in Dawuro Zone and the subjects of the study were: school student and physical education teachers of the school in the study area. This study employed descriptive survey research design to see the existing condition regarding the attitude of students toward sport skill program. In order to select the representative sample, simple random sampling technique of lottery method was used to include student, whereas comprehensive sampling technique was used to select teacher. Besides, purposive sampling technique was used to select department heads. To gather necessary information from the respondents, 
questionnaire was provided for teachers and students, while observation was held in the school. The data gathered through observation was analyzed by using narration after the data were recorded by the researcher. The data obtained through questionnaire was analyzed by using frequency, percentage and mean value, independent sample t-test. Accordingly, the major findings of the study were summarized below.

\subsection{Summary}

On basis of the major findings, the following points were obtained and the summary was made with respect to data obtained through observation data, characteristics of the respondents, perception of students and factors for negative attitude.

1. The major findings of the study with regard to students 'attitude toward sport skill

$>54.7 \%(\mathrm{n}=186)$ of student and $54.6 \%(\mathrm{n}=17)$ of teachers indicated that school students considering physical education as one of the worst lessons in school.

$>72.1 \%(\mathrm{n}=245)$ of student and $73.3 \%(\mathrm{n}=22)$ of teachers expressed that activities in physical education as boring because they always do

$>$ most of respondents, $58.2 \%(\mathrm{n}=198)$ of student and $66.7 \%(\mathrm{n}=20)$ of teachers indicated that students choose \& do what they wish in physical education and games

$>$ majority of respondents, $51.8 \%(\mathrm{n}=176)$ of student and $53.3 \%(\mathrm{n}=16)$ of teacher expressed that student do not go to school to do physical education but to learn other subject

$>$ Most of respondents, $73.3 \%(\mathrm{n}=22)$ of teachers with the calculated mean value of $(\mathrm{M}=2.84, \mathrm{SD}=1.60)$ of student and $(\mathrm{M}=2.13, \mathrm{SD}=0.86)$ of teachers and $\mathrm{t}$-test result $(\mathrm{t}=2.41 ; 0.01<0.05)$ affirms that student have low interest in learning physical education activities.

$>$ Vast majority of respondents, $51.9 \%(\mathrm{n}=197)$ of student and $56.7 \%(\mathrm{n}=17)$ of teachers indicated that student have low level of confidence in participating in physical exercise

$>$ Most of respondents, $86.5 \%(\mathrm{n}=294)$ of student and $90 \%(\mathrm{n}=27)$ of teachers indicated that student were failed to like teachers teaching method in practical classes

$>$ Regarding Student attitude towards to actual practice of sport skill that most of the respondents affirmed that students are reluctant to perform physical activity, students did not takes his/her turn to perform physical activities, majority of students do as they wish rather than about a given task, they did not ask their teacher to help them during learning task, they were not freely communicates with their teachers and partners, they were failed to prepare accuracy over physical activity and as well as there is domination of some students during physical activities in the study area.

2. The major findings of the study concerning factors influence the attitude of high school students towards sport skill

a) The vast majority of respondents, $72.4 \%(n=246)$ of student and $93.3 \%(n=28)$ of teachers indicated that lack of school facilities has effect on student participation in physical education.

b) Most of participant $58.2 \%(n=198)$ of students and $70 \%(n=21)$ of teachers were agreed to the point specifically cultural influences in school were as a major factor of student attitude towards to sport skill.

c) The obtained data concerning the factors influence the attitude of students towards physical education size of class in school, the poor economic status of students, poor teacher's efficiency, lack of teacher's lesson preparation (readiness), lack of use of teaching methods, lack of gender sensitivity, lack of interest in subject, peer influence ,absence of dressing house for female student's

d) The other challenging factors for students attitude towards physical education in which majority of participants affirmed that students are worried about making mistakes in physical activity program, fearful of injury in the study area, students lack of prior experience, little evaluation time for teachers due to large group, teacher not played a role in shaping perceptions of pupils towards physical education, teacher not demonstrate skills to pupils, physical education teachers failed to adapt socially by encouraging them to attempt to inspire each other in many of the activities, and as well as lack of balance between classroom learning and participation in physical education lessons

\section{The major findings of the study concerning students perceptions to the importance of the} course physical education at local levels

The majority of the respondents' responses about perceptions to the importance of the course physical education at local levels reveal that students were failed to perceive the contributions to mental health of physical education in the study area.

Most of the informants $83.5 \%(n=284)$ of students and $63.3 \%(n=19)$ of teacher frequently cited the negative perception of student to physical education in cooperation enhancement in the study area.

most of the informants, $85.9 \%(n=292)$ of students and $86.7 \%(n=26)$ of teacher disagreed to the variable in which respondents indicated student perceives that physical education class failed offer large variety of interesting activities in the study area. 
Majority of respondents, $87.1 \%(n=296)$ of students and $70 \%(n=21)$ of teacher disagreed to the variable, that most girls and boys were not enjoyed physical education classes in the study area.

majority of respondents, $83.5 \%(n=284)$ of students and $100 \%(n=30)$ of teacher disagreed to the variable, that student not perceive physical education as one of the best lessons which student has in school in the study area.

The respondents also assured that activities failed to provide opportunities for satisfying social experiences, student perceives PE not offers training for leadership, does not lead to a job, physical education activities provided were not fun, student perceives that physical education failed to promote emotional development and as well as students perceive that physical education failed to create opportunity in developing moral \& ethical conduct in the study area.

4. The major findings of the study with regard possible alternative measures should take so as to enhance students 'attitude toward sport skill

Among the possible alternative measures should take so as to enhance students 'attitude toward sport skill which were assumed to have important contribution to over-all students 'attitude of secondary schools in the study area, it was generally reported that the respondents affirmed that facilitating suitable teaching and learning environment were considered as mechanism to improve students' attitude towards to physical education and sport skill and developing qualified person in the study area

Most of the informants, $79.4 \%(n=270)$ of students and $56.7 \%(n=17)$ of teacher strongly agreed to the variable. The data revealed that making the subject available at regional and national examination and majority of respondents, $79.4 \%(n=270)$ of students and $80 \%(n=24)$ of teacher strongly agreed to the variable that suggests in providing enough time schedules for physical education was considered as mechanism to improve students' attitude towards to physical education and sport skill in the study area.

Majority of respondents, $57.4 \%(n=195)$ of students and $56.7 \%(n=17)$ of teacher strongly agreed to the variable, suggests that physical education activity skill should be well executed, teacher should vary skills taught so that pupils learn with ease physical education skills taught, the vast majority of respondents, $58.2 \%(\mathrm{n}=198)$ of students and $60 \%(\mathrm{n}=18)$ of teacher strongly agreed to the item that teacher should take into account differences in pupils abilities so that all are involved in the physical education lesson, teacher should regularly correct pupils in their execution of physical education skills to perform them correctly, teacher should use all the physical education lessons to teach pupils the subject, teacher should conduct physical education lesson as seriously and as well as the respondents also assured that physical education subject should be included in the program of every school were considered as mechanism to improve students' attitude towards to physical education and sport skill.

Other alternative strategies to improve students' attitude towards to physical education and sport skill, most of respondents affirmed that teacher allows students to share their ability with partners, encourages students to perform physical activity, teachers should encourages students to perform physical activity, teachers show each and every thing for the students, facilitates and assists the students while they are doing a given activities, the participant also ensured the teachers to correct the errors of students at the end of physical activity, and as well as the respondents also assured teachers should initiating passive students to take part in tasks execution in the study area.

\subsection{Recommendations}

* On basis of the conclusion, the following recommendations were put forwarded.

1. It is advisable that Physical education teachers should allow students to practice in class and they should execute around in the field to check whether students are practicing on the given skill and should provide necessary guidance along with immediate feedback for their students after task.

2. It is recommendable that Physical education teachers should build their interest as well as their students' interest ever since practice method plays great role in developing students' skill and minimize students' nervousness by advising students not to fear of any mistakes since mistakes are learning opportunities.

3. In order to overcome the problems beyond the capacity of classroom teachers, such as class size and supply of necessary sport materials, the school should work in collaboration with Woreda Education Office and community at large should build additional learning field and supplement the sport equipment with authentic materials as much as possible.

4. The Physical education teacher should develop students' interest to perform sport skill task through different method and build confidence as well as motivate students just by making the classroom welcoming by different game and free from frustration.

5. The stakeholders and physical education teachers should also allocate sufficient time for activities to increase each student's opportunity to practice and should motivate, encourage, comment on and use different physical activities that can create authentic, meaningful and realistic situation to enhance the practice of student.

6. Physical education teachers should properly use practice method to develop learners' abilities to compete 
and should develop their skill competence as well as students' health.

7. Physical education teachers as well as the school should put up positive attitude towards teaching sport skill through cooperative method since it is preferable to teach the skill, student-centered that all students to interact and improve students' proficiency of skill.

8. The methods and teaching styles used by the teachers should be appropriate with the Physical Education lessons in order to equip students with the necessary knowledge that enable them evaluate the importance of physical education with respect to physical, mental, emotional and social health

9. PE should be taught like other lessons as acquisition of movement skills and positive attitude to ensure the achievement of the PE objectives especially to reduce lifestyle diseases or non-communicable diseases. The overemphasis from stakeholders for schools to do well in national exams should be checked as it has been shown by various studies that it is a major reason as to why teachers are using PE lessons to teach examinable subjects thereby forcing teachers and pupils to develop negative attitude towards PE.

10. The time and number of periods given to Physical Education should be increased per a week and extracurricular activities related to physical education should be offered to develop the students' knowledge, skill, and ethical value in physical education.

11. More weight should be given to physical education this could be achieved by:

$>$ Facilitating the teaching learning process based on the curriculum and contents designed for physical education, the needs and expectations of the students, students learning ability and other related factors.

$>$ Devising evaluation techniques compatible with the nature of the subject establishing objective criteria for assessment.

$>$ Giving in-service training for physical education teachers based on their level of qualification.

$>$ Providing training in educational and psychological aspects of teacher student interaction

\section{REFERENCES}

* Barney :(2003). The attitude and perception of students all age towards physical education. Behavior, Engle woods cliffs, NJ; prentice -hall.

* Best, J.W\&Kahn, J.V (2003). Research in Education New Delhi; Prentice Hall PL.

* Bob Uri chuck :(2015). Motivating your mind inspiring your sprint.

* Brumbach, W.B., \& Cross, J.A. (1965). Attitude towards physical education of male students entering university of Oregon. Research quarterly 36(1) 10-16.

* Catherine, D. (2013). Advanced Research Methods. A Practical Guide for Social Science Research. Constable and Robinson.

* Chen, A. and P.W. Darst, 2001. Situational interest in physical education: A function of learning task design. Res. Quar. Exerc. Sport, 72: 150-164.

* Center for disease control and prevention (2002) youth risky behavior surveillance united state ( 2002).morbidity and mortality weekly report (ss-4)-1-64.

* Chung, M. \&Phillips, D.A (2002). The relationship between Attitude towards physical education and leisure time exercise in high school students the physical educator 59,126-138.

* Creswell, J.W. (2003). Research Design: Qualitative, Quantitative and Mixed Methods Approaches. London: Sage. $2^{\text {nd }}$ ed.

* Cohen, L. Manion, L. and Morrison, K. (2007).Research Methods in Education (6 ${ }^{\text {th }}$ ed.). London: Routledge.

* Grout, and Long (2009). Improving teaching and learning ( $4^{\text {th }}$ ed).New York Holt Rinchart and winstm

* Gay, L.R. and Airasian, P. (2003). Education Research: Competencies for Analysis and Application. 6th Edition. New Jersey: Merril.

* Hagger, M.S., N.L. Chatzisarantis and J.H. Biddle, 2002. A meta-analytic review of the theories of reasoned action and planned behavior in physical activity: Predictive validity and the contribution of additional variable. J. Sport Exerc. Psychol., 24: 3-32.

* Hilde brand K.M, \& Johnson, D, J. (2001). Determinates collage physical activity class enrollment: implication for high school physical education. The physical educator, 58. 51-56.

* Jwan, J. (2010). Conducting Quantitative Research: Current Trends \&Developments: MoiUniversity $5^{\text {th }}$ Campus Wide Research Workshop.

* Kedra cherry (htt: //plus google.com). Can be defined as attitude have a powerful influence on behavior.(physiologist)

* Kerlinger, F.N. (2003). Foundations of Behavioral Research, Harcourt Brace Jovanovich.

* Kothari, C.R. (2004). Research Methodology: Methods and Techniques.New Delhi, New Age International (P) Ltd.

* Kothari, C.R. (2008). Research Methodology, Methods and Techniques. (2 ${ }^{\text {nd }}$ ed.) New Delhi: Pitman 
Publishers.

* National Association for sport and physical education (2001). An association of American alliance for health physical education, recreation and dance.

* National association for sport and physical education (2012): an association of American alliance for health and physical education .recreation and dance.

* Lee, A.M., 2004. Promoting lifelong physical activity through quality physical education. J. Phys. Educ. Rec. Dance, 75: 21-26.

* Ontario (2010) physical education; Canada education phsiqueetsnt.

* Popham, J (2005). Student's attitude towards physical education: Journal of teaching in physical education

* Rink, J., 2006. Teaching Physical Education for Learning. 6th Edn., McGraw-Hill, New York, ISBN: 0073376523 , pp: 416.

* US department of health human service (2000) healthy people 2010(Washington D.C US government printing office.

* Subramanian, P.R. and S. Silverman, 2002. Using complimentary data: An investigation of student attitude in physical education. J. Sport Pedagogy, 8: 74-91.

Biography of author

The author was born in 1978 in Loma Woreda in Dawuro Zone of Southern Regional State Ethiopia. He attended his elementary, senior secondary school and secondary school education at Loma and Waka School respectively. Then, he joined Hawassa Teacher Training collage and received Diploma in teaching physical education profession in 2005. He had got degree in sport science from Dilla university and after graduation He taught for 7 year secondary school. Then, after 7 years' service, I joined Hawassa University to attend Msc degree program in sport science through summer in-service program and graduated in 2012. As well has the author have BA degree in Management. The author had 10 years of teaching experience. Finally, he joined the woliata Sodo University in 2018 academic year to as lecturer. The author is married and is a father of 1children. Now a day, the author has been working as lecturer in Department of sport science in Woliata Sodo University. 